\title{
G

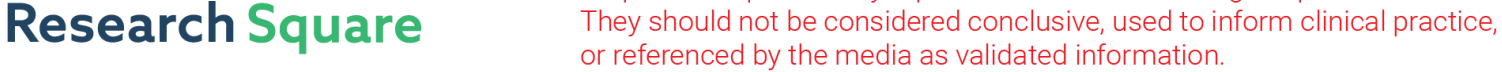 \\ Entrapment Predicts First-Onset Suicidal Ideation: A Longitudinal Study in Medical Students
}

\section{Suping Wang}

Shanghai Jiao Tong University School of Medicine

\section{Rui Zhu}

School of Public Health, Shanghai Jiao Tong University School of Medicine

\section{Hantao Wu}

School of Public Health, Shanghai Jiao Tong University School of Medicine

\section{Sicong Li}

School of Public Health, Shanghai Jiao Tong University School of Medicine

\section{Xinyi Liu}

School of Public Health, Shanghai Jiao Tong University School of Medicine

Yong Cai ( $\nabla$ caiyong202028@hotmail.com )

School of Public Health, Shanghai Jiao Tong University School of Medicine

\section{Ruijie Gong}

Xuhui Center for Disease Control and Prevention

\section{Research Article}

Keywords: entrapment, suicidal ideation, medical students, predict

Posted Date: January 18th, 2022

DOI: https://doi.org/10.21203/rs.3.rs-1222696/v1

License: () (1) This work is licensed under a Creative Commons Attribution 4.0 International License.

Read Full License 


\section{Abstract}

\section{Background}

The prevalence of suicidal ideation among medical students is high. Evidences indicate that entrapment is a predicting factor of suicidal ideation. This study aimed to (1) investigate the prevalence rates of firstonset suicidal ideation among Chinese medical students, (2) explore the predictive effects of alteration of entrapment on first-onset suicidal ideation.

\section{Methods}

This longitudinal study was conducted between 2018 and 2019, included 211 new-enrolled medical students in Shanghai. Socio-demographic (gender, major, parents' income and academic performance), psychological (entrapment, depression, loneliness, defeat, social support and interpersonal needs) variables and suicidal ideation were collected by anonymous questionnaire. Samples were divided into 4 subgroups according to their exposure to entrapment (control, new-onset, reduced and persistent group). The primary outcome, first-onset suicidal ideation, was defined as absent suicidal ideation at baseline but present at follow-up.

\section{Results}

$54.98 \%$ of the participants $(116 / 211)$ were female and $76.78 \%(162 / 211)$ majored in clinical medicine. $6.16 \%$ of the participants $(16 / 211)$ reported first-onset suicidal ideation in the follow-up survey. $17.54 \%$ (37/211) reported new-onset entrapment while 12.80\% (27/211) reported persistent entrapment during follow-up. Compared to control group who reported no perceived entrapment at baseline and follow-up, participants reported new-onset entrapment had the highest risk of new-onset suicidal ideation (odd ratios $[\mathrm{OR}]=14.700,95 \%$ confidence interval $[\mathrm{Cl}]=2.906-74.364$; adjusted $\mathrm{OR}=8.798,95 \% \mathrm{Cl}=1.588-48.757$; multivariate $\mathrm{OR}=8.238,95 \% \mathrm{Cl}=1.394-48.693)$.

\section{Conclusion}

New-onset entrapment can significantly predict suicidal ideation. Therefore, more attention should be attached to new-onset entrapment when it comes to suicidal ideation intervention.

\section{Background}

Suicide behavior (including suicidal ideation, suicidal plan, suicidal attempt, suicide) have aroused wide concern due to its posing threat to global health. Medical students, given the length of medical training and relatively onerous academic burden[1], are under higher risk of suicidal ideation with a prevalence of $11.1 \%$ in a global systematic review[2] and $17.9 \%$ in China[3], strongly predictive of suicide attempts and deaths[4]. Whereas, as pointed out by Blacker[5], suicide rates of medical students were still infrequently reported in the historical and international literature, which indicated that the prevalence would beyond 
what reported. Consequently, exploration of the generation and features of suicidal ideation among medical students to reveal future intervention targets is imperative[6].

Suicidal ideation is defined as thinking about, considering, or planning suicide[7]. Decades of study showed that the development of suicide ideation is complex[8,9]. There was a wide range of psychological and social factors that act to develop suicidal ideation[10], including loneliness[11], unmet interpersonal needs [12], depression [13], self-esteem[14],defeat and entrapment[15].

Entrapment is a strong motive to escape, with the feeling of being blocked[16] and consists of two components: external entrapment (the feeling of being blocked by external factors such as the living environment, others' opinions, obligations) and internal entrapment (one's internal feelings and thoughts) $[15,17,18]$. According to the integrated motivational-volitional model (IMV model), defeat and humiliation transit to entrapment with certain moderators including poor coping and poor problem solving [19], and then entrapment translates to suicidal ideation with the enhancement or reduction role of motivational moderator [20]. Recent years have witnessed burgeoning interest in entrapment as well as its potential mechanism leading to suicidal ideation. For example, in a cross-section study in Chinese adolescents, entrapment was proved to be significantly related with suicidal ideation and factors like thwarted belongingness and perceived burdensomeness could reinforce the relationship[21]. Furthermore, it has been repetitiously proved that entrapment mediated the relationship between defeat and suicidal ideation, with resilience as a possible alleviating factor[22, 23]. Nevertheless, though many previous studies have dug into the entrapment-suicidal ideation relationship, few of them focus on medical students, the group of population at higher risk of suicide[24]. In addition, most of them are cross-sectional studies[2, 20]that only focus on correlation of entrapment and suicidal ideation rather than longitudinal studies that are able to explore alteration of entrapment level in suicidal ideation cases. A 4-month follow-up research was conducted to reveal the role of entrapment in predicting suicidal ideation[25], thus giving us inspiration to probe into the relationship within a longer period and divide the participants into different groups based on altered levels of exposure to entrapment. Another remarkable disadvantage with previous studies is that few of them were conducted in Asia or low- and middle-income countries[26], which account for a large portion of global suicide deaths, revealing the need to broaden the scope of longitudinal research on suicidal ideation in terms of countries and regions. To the best of our knowledge, no such prospective study assessing entrapment alteration as a predictor of suicidal ideation among medical students has ever been conducted.

Therefore, a 12-month follow-up longitudinal study has been designed, aiming to (1) investigate the prevalence rates of first-onset suicidal ideation among Chinese medical students, (2) explore the predictive effects of alteration of entrapment on first-onset suicidal ideation.

\section{Methods}

\subsection{Participants and procedures}


The setting of present study was one well-known medical school in Shanghai. All eligible freshmen met inclusion criteria below were invited to participate at the first year of university for baseline survey $(\mathrm{N}=656)$. The progress of investigation was mentioned in our previous study[27]. The baseline (T0) survey was conducted from March to May 2018. Since the questionnaire was anonymous, the last four and three digits of participants' identity card number and phone numbers would be collected only for matching purposes. And all eligible freshmen met inclusion criteria were invited again to complete the follow-up survey(T1) at the second year of school (from June to July 2019).

Questionnaire with any missing item was regarded as invalid. Casual samples are also excluded during data processing. Any participant reported ever had suicidal ideation at baseline was excluded. Finally, 12month follow-up cohort was established( $\mathrm{N}=211)$ (see Fig.1).

Inclusion criteria:(1) undergraduates enrolled in 2017 for the first time, (2) proficiency in Chinese.

\subsection{Ethics}

The study was approved by the Ethics Committee of Shanghai Jiao Tong University School of Medicine (SJUPN-201813). Participants were guaranteed that the collected data would only be accessed by the researchers. Once signed informed consent, participants were agreed to participate in this investigation. All participants were free to ask any questions and to withdraw if they did not wish to continue and they were also aware of that the last four and three digits of participants' identity card number and phone numbers would be collected only for matching purposes which could not identify any participant.

\subsection{Measures}

\subsubsection{Socio-demographic variables}

Socio-demographic variables included gender ('male' and 'female'), major ('Clinical medicine' and 'nonclinical medicine'), parents' income ('High', 'Average' vs 'Low'), and academic performance ('good (the first third in class)', 'average' or 'Poor (the last third in class)') were measured at the baseline survey.

\subsubsection{Psychological variables}

Entrapment. Entrapment was assessed with the Entrapment Scale [28], a 16-item Likert-type questionnaire. The questionnaire was focused on the subjective feeling of entrapment, with every item ranging from 0 (not at all like me) to 4 (extremely like me). Question 1-10 were focused on external entrapment, while question 11-16 concentrate on internal entrapment. A higher sum scored indicated a higher level of entrapment, and the cut-off point was set at 16 , the upper quartile of entrapment scores at T0. Participants with entrapment scores higher than 16 were defined as perceived entrapment status at the time of investigation. The Chinese vision of Entrapment Scale was proved valid and reliable in Chinese medical students[29] (Cronbach's alpha=0.951; range 0-64). 
Depression. The level of depression was measured using 9-item Patient Health Questionnaire (PHQ-9) [30], a Likert questionnaire composed of 9 items. Participants were asked about the frequency of depressive symptoms in the past 2 weeks. Every item ranged from 1 (not at all) to 4 (almost every day). The higher the sum score, the severer the participant's depression degree. With reference to advanced research[30], scoring above 13 was considered as existed depression. The Chinese version of PHQ-9 questionnaire had a good reliability and validity among college students[31] .(Cronbach's alpha=0.871; range 9-36)

Loneliness. The 8-item UCLA loneliness Scale was used to evaluate loneliness among participants[32]. There are 8 items in the Likert questionnaire, ranging from 1 (not at all) to 4 (almost every day). The items were concentrated on participants' subjective feeling of loneliness. A higher total score corresponded to higher level of loneliness. Since no standard cut-off point was available, the upper quartile (T0), 17, was set as the cut-off point. Participants with ULS-8 scores higher than 17 were defined as relatively high level of perceived loneliness at the time of investigation. (Cronbach's alpha=0.829; range 8-29)

Defeat. Defeat Scale was used to assess participants' feeling of being defeated[28], which is a questionnaire of 16 items, with every item ranging from 0 (never) to 4 (always). The Chinese vision of Defeat Scale was proved valid and reliable in Chinese medical students[33]. A higher total score indicated a severer feeling of defeat of the participant. The upper quartile (TO) 18 was used as the cut-off point. Participants with defeat scores higher than 18 were defined as relatively high level of perceived defeat at the time of investigation. (Cronbach's alpha $=0.907$; range $0-52$ )

Social support. Multiple Scales of Perceived Social Support was used for measurement of participants' social support. MSPSS is composed of 12 questions about participants' subjective feelings of support from family, friends and others. The MSPSS has been widely used in multiple countries, which showed good reliability and validity[34,35]. The higher total score meant more social support, hence the lower quartile (T0), 67, was picked as the cut-off point. Participants with MSPSS scores lower than 67 were defined as relatively low level of perceived social support at the time of investigation. (Cronbach's alpha=0.960; range 33-84)

Interpersonal needs. The 15-item Interpersonal Needs Questionnaire scale included six questions to measure perceived burdensomeness and nine questions to assess thwarted belongingness[36], ranging from 1 (strongly disagree) to 7 (strongly agree). With 6 of the items were reverse-scored, a higher sum score meant higher status of TB and PB of the participant. The upper quartile (T0), 37, was set as the cutoff point. Participants with INQ-15 scores higher than 37 were defined as relatively high level of unmet interpersonal needs at the time of investigation. The Chinese version of the questionnaire had good reliability and validity among Chinese college students[37]. (Cronbach's alpha=0.895; range 15-78).

\subsubsection{Outcome}

First-onset suicidal ideation. Suicidal ideation was measured by asking students: "Have you ever had thoughts of taking your own life?" (T0) and "During the past 12 months have you had thoughts of taking 
your own life?" (T1)[38]. A "yes" for the first question was valued as existed lifetime suicidal ideation. And a "yes" for the latter question was regarded as having suicidal ideation during 12 months. Thus, firstonset suicidal ideation was defined as absent suicidal ideation at T0 but present at T1.

\subsection{Statistical analysis}

In order to estimate the association between entrapment and first-onset suicidal ideation, all 211 samples were divided into 4 subgroups according to their exposure to entrapment. All the covariates except for entrapment were collected at the same time when the outcome was measured (T0). Statistical Package for Social Sciences (version 26.0 for Windows; IBM SPSS Statistics, Armonk, NY, USA) was used for descriptive analysis and logistic regression. Several logistic regression models were conducted afterwards to examine difference between the subgroups. Statistical significance was claimed for $p<0.05$.

\section{Results}

\subsection{Socio-demographic and psychological characteristics of participants}

As shown in Table 1, 54.98\% of the participants (116/211) were female and 76.78\% (162/211) majored clinical medicine. Most students $(65.88 \%, 139 / 211)$ considered their parents' income as average while about half $(58.29 \%, 123 / 211)$ participants reported average academic performance. The rate of perceived entrapment, depression, loneliness, defeat, social support and unmet interpersonal need were $21.80 \%$ (46/211), 45.02\% (95/211), 23.70\% (50/211), 24.64\% (52/211), 73.93\% (156/211) and $24.17 \%(51 / 211)$.

$6.16 \%$ of the participants $(16 / 211)$ reported occurring suicidal ideation in the past year. Among all variables measured at baseline, only depression and loneliness showed significant relationship with firstonset suicidal ideation $(\mathrm{OR}=4.431,5.943)$. 
Table 1

Socio-demographic and psychological variables associated with suicidal ideation.

\begin{tabular}{|c|c|c|c|}
\hline & Frequency & Percentage & OR $(95 \% \mathrm{Cl})$ \\
\hline \multicolumn{4}{|l|}{ Socio-demographic variables } \\
\hline \multicolumn{4}{|l|}{ Gender } \\
\hline Male & 95 & 45.02 & $0.346(0.092-1.294)$ \\
\hline Female & 116 & 54.98 & Ref. \\
\hline \multicolumn{4}{|l|}{ Major } \\
\hline Clinical medicine & 162 & 76.78 & $0.662(0.195-2.250)$ \\
\hline Non-clinical medicine & 49 & 23.22 & Ref. \\
\hline \multicolumn{4}{|l|}{ Parents' income } \\
\hline Low & 26 & 12.32 & $0.573(0.057-5.812)$ \\
\hline Average & 139 & 65.88 & $0.992(0.257-3.833)$ \\
\hline High & 46 & 21.80 & Ref. \\
\hline \multicolumn{4}{|l|}{ Academic performance } \\
\hline Poor & 35 & 16.59 & $0.900(0.201-4.032)$ \\
\hline Average & 123 & 58.29 & $0.407(0.113-1.469)$ \\
\hline Good & 53 & 25.12 & Ref. \\
\hline \multicolumn{4}{|l|}{ Psychological variables } \\
\hline \multicolumn{4}{|l|}{ Entrapment } \\
\hline High & 46 & 21.80 & $1.651(0.484-5.626)$ \\
\hline Low & 165 & 78.20 & Ref. \\
\hline \multicolumn{4}{|l|}{ Depression } \\
\hline High & 95 & 45.02 & $4.431(1.183-16.597)^{\star}$ \\
\hline Low & 116 & 54.98 & Ref. \\
\hline \multicolumn{4}{|l|}{ Loneliness } \\
\hline High & 50 & 23.70 & $5.943(1.848-19.112)^{\star \star}$ \\
\hline Low & 161 & 76.30 & Ref. \\
\hline${ }^{*} p<0.050 ; * * p<0.010$ & & & \\
\hline
\end{tabular}




\begin{tabular}{|c|c|c|c|}
\hline & Frequency & Percentage & OR $(95 \% \mathrm{Cl})$ \\
\hline \multicolumn{4}{|l|}{ Defeat } \\
\hline High & 52 & 24.64 & $2.008(0.627-6.433)$ \\
\hline Low & 159 & 75.36 & Ref. \\
\hline \multicolumn{4}{|l|}{ Social support } \\
\hline Low & 55 & 26.07 & $2.606(0.836-8.127)$ \\
\hline High & 156 & 73.93 & Ref. \\
\hline \multicolumn{4}{|l|}{ Interpersonal needs } \\
\hline High & 51 & 24.17 & $2.914(0.932-9.112)$ \\
\hline Low & 160 & 75.83 & Ref. \\
\hline \multicolumn{4}{|c|}{ First-onset suicidal ideation } \\
\hline Yes & 13 & 6.16 & \\
\hline No & 198 & 93.84 & \\
\hline${ }^{*} p<0.050 ; * \star p<0.010$ & & & \\
\hline
\end{tabular}

OR: univariate odds ratio

95\% Cl: 95\% confidence interval

Ref.: reference category

\subsection{Suicidal Ideation Of Subgroups}

Table 2 displayed that $6.16 \%$ of the total participants (13/211) reported suicidal ideation in past one year.

There were significant differences of suicidal ideation prevalence among 4 subgroups $\left(\chi^{2}=16.269\right.$, $p=0.001)$ that those who newly onset perceived entrapment at T1 had the highest prevalence $(18.92 \%$, $7 / 37$ ). There was no significant difference of socio-demographic characteristics among 4 subgroups except for gender. 
Table 2

Subgroup division and suicidal ideation within 4 subgroups.

\begin{tabular}{|c|c|c|c|c|c|}
\hline \multirow[t]{2}{*}{ Group } & \multicolumn{2}{|c|}{ Entrapment status } & \multirow[t]{2}{*}{ Group size } & \multicolumn{2}{|c|}{ suicidal ideation } \\
\hline & TO & $\mathrm{T} 1$ & & Number & Raw\% \\
\hline Control & - & - & 128 & 2 & $1.56 \%$ \\
\hline Reduced & + & - & 19 & 1 & $5.26 \%$ \\
\hline New-onset & - & + & 37 & 7 & $18.92 \%$ \\
\hline Persistent & + & + & 27 & 3 & $11.11 \%$ \\
\hline Total & & & 211 & 13 & $6.16 \%$ \\
\hline
\end{tabular}

\subsection{Logistic Regression Models For Suicidal Ideation}

Logistic regression models for entrapment and suicidal ideation were presented in Table 3. Compared to control group who reported no perceived entrapment at T0 and T1, participants reported new-onset entrapment at $\mathrm{T} 1$ had the highest risk of new-onset suicidal ideation ( $\mathrm{OR}=14.700,95 \% \mathrm{Cl}=2.906-74.364$; $\mathrm{ORa}=8.798,95 \% \mathrm{Cl}=1.588-48.757 ; \mathrm{ORm}=8.238,95 \% \mathrm{Cl}=1.394-48.693)$. Furthermore, participants reported perceived persistent entrapment at $\mathrm{T} 0$ and $\mathrm{T} 1$ also had a higher risk of developing suicidal ideation $(\mathrm{OR}=7.875,95 \% \mathrm{Cl}=1.555-27.175)$ without any adjusted. 
Table 3

Different models of entrapment exposure with risk of suicidal ideation conversion.

\begin{tabular}{|c|c|c|c|c|c|c|c|c|c|}
\hline \multirow[t]{2}{*}{ Group } & \multicolumn{3}{|c|}{ Model 1} & \multicolumn{3}{|c|}{ Model 2} & \multicolumn{3}{|c|}{ Model 3} \\
\hline & $p$ & $\mathrm{OR}^{\mathrm{a}}$ & $95 \% \mathrm{Cl}$ & $p$ & ORab & $95 \% \mathrm{Cl}$ & $\mathrm{p}$ & ORm & $95 \% \mathrm{Cl}$ \\
\hline $\begin{array}{l}\text { New- } \\
\text { onset }\end{array}$ & 0.001 & 14.700 & $\begin{array}{l}2.906- \\
74.364\end{array}$ & 0.013 & 8.798 & $\begin{array}{l}1.588- \\
48.757\end{array}$ & 0.020 & 8.238 & $\begin{array}{l}1.394- \\
48.693\end{array}$ \\
\hline Reduced & 0.316 & 3.500 & $\begin{array}{l}0.302- \\
40.589\end{array}$ & 0.694 & 1.677 & $\begin{array}{l}0.128- \\
21.947\end{array}$ & 0.736 & 1.669 & $\begin{array}{l}0.085- \\
32.906\end{array}$ \\
\hline Persistent & 0.028 & 7.875 & $\begin{array}{l}1.249- \\
49.668\end{array}$ & 0.282 & 3.037 & $\begin{array}{l}0.401- \\
23.014\end{array}$ & 0.388 & 3.017 & $\begin{array}{l}0.246- \\
37.034\end{array}$ \\
\hline Control & - & Ref. & - & - & Ref. & - & - & Ref. & - \\
\hline \multicolumn{10}{|c|}{ a OR: odds ratio of Model 1 included only entrapment. } \\
\hline \multicolumn{10}{|c|}{$\begin{array}{l}\text { b ORa: odds ratio adjusted of Model } 2 \text { included entrapment and significant variables (depression and } \\
\text { loneliness) measured at T0. }\end{array}$} \\
\hline
\end{tabular}

\section{Discussion}

The prevalence of first-onset suicidal ideation among medical students in their second year of school were reported at the rate of $6.16 \%$ in our study, lower than that of the crude summary prevalence of $11.1 \%$ among medical students during medical school[39].

The enlightening part of our study is the robust predictor of first-onset suicidal ideation, new-onset entrapment. In line with our result, multiple studies and models agreed to demonstrate the leading significance of entrapment in the formation of suicidal ideation [22, 40], but were divided by diversified study designs in regard to subjects, psychological variables and so on [20,25, 41,42]. Most of the previous studies are cross-sectional studies, while there are several longitudinal researches attempting to achieve real-time observation of subjects' the variability of certain psychological factors by assessing them multiple times per day $[25,43,44]$. While limited long-term longitudinal researches on this topic has been done before, our study is the first one with a follow-up period as long as one year. With comparison to existing researches, the most innovative point of this longitudinal survey is to divide the level of exposure to entrapment into 4 classifications so as to explore the relevance between different stages of entrapment and suicidal ideation conversion. Our research demonstrates the close relation between entrapment, especially new-onset entrapment with first-onset suicidal ideation, which supports the IMV model, corroborating that entrapment is an essential predictor of first-onset suicidal ideation. 
New-onset entrapment is mostly related to suicidal ideation, possibly because the participants who perceived new-onset entrapment had been in a situation of external or internal pressure shortly and may encounter a stronger subjective feeling of no way to flee and desperation, while participants who were positive in persistent entrapment are more inclined to get used to the dilemma they met, which may lower the chance to think about extreme solutions such as suicide. In accord with IMV model, the protective motivational moderators may have not taken shape yet in comparison to the perception persistent entrapment, which may have developed tolerance to entrapment. There is no valid basis of this assumption yet, thus further studies are needed to verify the relevance of new-onset entrapment and persistent entrapment with suicidal ideation conversion.

There are several limitations in our current research that should be taken into account. Firstly, as a longitudinal study with a follow-up period of 12 months, loss of follow-up appears to be a problem. Only $32.16 \%(211 / 656)$ of the eligible freshmen completed the follow-up survey. Secondly, the sample is restricted to the freshmen of one medical school, subsequently leading to a relatively small sample size, which may contribute to sampling error. However, the relatively small sample size guaranteed a more reliable follow-up. Thirdly, the evaluation tool for suicidal ideation used in this study is a set of simplified questions which was originated from previous studies. If we could use scale evaluating not only suicidal ideation but also suicide behaviors, there may be more deep-going findings. Ultimately, according to the study, entrapment possibly work as a mediator in the whole course of development of suicidal ideation, therefore, further research targeting the pathway is required in order to explore the generating process of suicidal ideation and intervention.

\section{Conclusions}

Since entrapment has been corroborated to be fluctuating, regular follow-up of the level of entrapment could be an effective measure of screening and preventing suicidal ideation conversion given its significance in suicidal ideation conversion. With reference to IMV model, whoever is found to have a perception of entrapment, especially new-onset entrapment, should be more concerned and guarded against motivational moderators such as thwarted belongingness, burdensomeness, lack of future thoughts, lack of social support, negative attitudes. To sum up, more attention should be attached to newonset entrapment when it comes to suicidal ideation intervention.

\section{Abbreviations}

OR

odd ratios

$\mathrm{Cl}$

confidence interval

IMV model

integrated motivational-volitional model

Ref. 
reference category

\section{Declarations}

\section{Ethical approval and consent to participate}

The study was approved by the Ethics Committee of Shanghai Jiao Tong University School of Medicine (SJUPN-201813). Informed, written consent was obtained from all individual participants included in the study. All methods were carried out in accordance with relevant guidelines and regulations.

\section{Consent for publication}

Not applicable.

\section{Availability of Data and Materials}

The datasets generated and/or analysed during the current study are not publicly available due to confidentiality agreement but are available from the corresponding author on reasonable request.

\section{Competing interests}

The authors declare they have no competing interests.

\section{Funding}

This work is funded by the National Key R\&D Program of China under Grant 2020YFC2006400, Shanghai Three-year Action Plan for Public Health under Grant GWV-10.2-XD13, GWV-10.1-XK15, GWV-10.1-XK18, Strategic collaborative innovation team under Grant SSMU-ZLCX20180601, the 13th Innovation

Training Program for Students of Shanghai Jiao Tong University School of Medicine under Grant 1319016 and Yangtze River Delta Regional Leading Talents Research Project on Immunization under Grant CSJP033.

\section{Authors' contribution}

$\mathrm{CY}$ contributed to the conceptualization. WSP contributed to design of the work and supervision. ZR contributed to acquisition, analysis and interpretation of data, and the drafting of the manuscript. WHT, LSC and LXY contributed to the acquisition, analysis and interpretation of data. GRJ contributed to the critical revision of the analysis, drafting and editing of the manuscript. All authors contributed to the critical revision of the paper and approved the final manuscript for publication.

\section{Acknowledgements}

We acknowledge all participants and interviewers involved in our research. 


\section{References}

1. Coentre R, Gois C: Suicidal ideation in medical students: recent insights. Adv Med Educ Pract 2018, 9:873-880.

2. Rotenstein LS, Ramos MA, Torre M, Segal JB, Peluso MJ, Guille C, Sen S, Mata DA: Prevalence of Depression, Depressive Symptoms, and Suicidal Ideation Among Medical Students A Systematic Review and Meta-Analysis. Jama-J Am Med Assoc 2016, 316(21):2214-2236.

3. Sun L, Zhou C, Xu L, Li S, Kong F, Chu J: Suicidal ideation, plans and attempts among medical college students in china: The effect of their parental characteristics. Psychiatry Res 2017, 247:139143.

4. Nock MK, Borges G, Bromet EJ, Alonso J, Angermeyer M, Beautrais A, Bruffaerts R, Chiu WT, de Girolamo G, Gluzman $S$ et al: Cross-national prevalence and risk factors for suicidal ideation, plans and attempts. Br J Psychiatry 2008, 192(2).

5. Blacker CJ, Lewis CP, Swintak CC, Bostwick JM, Rackley SJ: Medical Student Suicide Rates: A Systematic Review of the Historical and International Literature. Acad Med 2019, 94(2):274-280.

6. Gishen F: Suicide among medical students. BMJ 2019, 366:I5465.

7. Klonsky ED, May AM, Saffer BY: Suicide, Suicide Attempts, and Suicidal Ideation. Annu Rev Clin Psychol 2016, 12:307-330.

8. Klonsky ED, Saffer BY, Bryan CJ: Ideation-to-action theories of suicide: a conceptual and empirical update. Curr Opin Psychol 2018, 22:38-43.

9. Nock MK, Borges G, Bromet EJ, Alonso J, Angermeyer M, Beautrais A, Bruffaerts R, Chiu WT, de Girolamo G, Gluzman S et al: Cross-national prevalence and risk factors for suicidal ideation, plans and attempts. Br J Psychiatry 2008, 192(2):98-105.

10. Klonsky ED, May AM: Differentiating suicide attempters from suicide ideators: a critical frontier for suicidology research. Suicide Life Threat Behav 2014, 44(1):1-5.

11. Lasgaard $M$, Goossens $L$, Elklit $A$ : Loneliness, depressive symptomatology, and suicide ideation in adolescence: cross-sectional and longitudinal analyses. J Abnorm Child Psychol 2011, 39(1):137150.

12. Joiner T: Why people die by suicide. Amwa Journal American Medical Writers Association Journal 2005(3):2082-2083.

13. Choi SB, Lee W, Yoon J-H, Won J-U, Kim DW: Risk factors of suicide attempt among people with suicidal ideation in South Korea: a cross-sectional study. BMC Public Health 2017, 17(1):579.

14. Bhar S, Ghahramanlou-Holloway M, Brown G, Beck AT: Self-esteem and suicide ideation in psychiatric outpatients. Suicide Life Threat Behav 2008, 38(5):511-516.

15. Ya-Min LI, Lei XY, Zhang D, Liu L, Tang SY: Determinant Factors of Suicidal Ideation among College Students: a Meta-analysis. Chinese Journal of Clinical Psychology 2014.

16. Gilbert P, Allan S: The role of defeat and entrapment (arrested flight) in depression: an exploration of an evolutionary view. Psychological medicine 1998, 28(3):585-598. 
17. Gooding P, Tarrier N, Dunn G, Shaw J, Awenat Y, Ulph F, Pratt D: The moderating effects of coping and self-esteem on the relationship between defeat, entrapment and suicidality in a sample of prisoners at high risk of suicide. Eur Psychiatry 2015, 30(8):988-994.

18. Taylor PJ, Gooding P, Wood AM, Tarrier N: The role of defeat and entrapment in depression, anxiety, and suicide. Psychol Bull 2011, 137(3):391-420.

19. Klonsky ED, Saffer BY, Bryan CJ: Ideation-to-action theories of suicide: a conceptual and empirical update. Current Opinion in Psychology 2018, 22:38-43.

20. Teismann T, Brailovskaia J: Entrapment, positive psychological functioning and suicide ideation: A moderation analysis. Clin Psychol Psychother 2020, 27(1):34-41.

21. Li X, Ren Y, Zhang X, Zhou J, Su B, Liu S, Cai H, Liu J, You J: Testing the Integrated MotivationalVolitional Model of Suicidal Behavior in Chinese Adolescents. Arch Suicide Res 2020:1-17.

22. Wetherall K, Robb KA, O'Connor RC: An Examination of Social Comparison and Suicide Ideation Through the Lens of the Integrated Motivational-Volitional Model of Suicidal Behavior. Suicide Life Threat Behav 2019, 49(1):167-182.

23. Zortea TC, Gray CM, O'Connor RC: Perceptions of Past Parenting and Adult Attachment as Vulnerability Factors for Suicidal Ideation in the Context of the Integrated Motivational-Volitional Model of Suicidal Behavior. Suicide Life Threat Behav 2020, 50(2):515-533.

24. Atienza-Carbonell B, Balanzá-Martínez V: Prevalence of depressive symptoms and suicidal ideation among Spanish medical students. Actas Esp Psiquiatr 2020, 48(4):154-162.

25. Owen R, Dempsey R, Jones S, Gooding P: Defeat and Entrapment in Bipolar Disorder: Exploring the Relationship with Suicidal Ideation from a Psychological Theoretical Perspective. Suicide Life Threat Behav 2018, 48(1):116-128.

26. Guzmán EM, Cha CB, Ribeiro JD, Franklin JC: Suicide risk around the world: a meta-analysis of longitudinal studies. Soc Psychiatry Psychiatr Epidemiol 2019, 54(12):1459-1470.

27. Gong R, Zhang Y, Long R, Zhu R, Li S, Liu X, Wang S, Cai Y: The Impact of Social Network Site Addiction on Depression in Chinese Medical Students: A Serial Multiple Mediator Model Involving Loneliness and Unmet Interpersonal Needs. International Journal of Environmental Research and Public Health 2021, 18(16).

28. Gilbert P, Allan S: The role of defeat and entrapment (arrested flight) in depression: an exploration of an evolutionary view. Psychol Med 1998, 28(3):585-598.

29. Suping GRLJWYCYW: Validity and reliability of the Chinese vision of the Entrapment Scale in medical students. Chinese Mental Health Journal 2019, 33(5):393-397.

30. Kroenke K, Spitzer RL, Williams JB: The PHQ-9: validity of a brief depression severity measure. J Gen Intern Med 2001, 16(9):606-613.

31. Wei L: A Research on Psychological Health Status and Psychological Disorder Prevention among Freshmen of Shanghai Colleges. Shanghai,China: Shanghai Jiaotong University School of Medicine; 2013. 
32. Hays RD, DiMatteo MR: A short-form measure of loneliness. J Pers Assess 1987, 51(1):69-81.

33. TANG Hua WS-p, GONG Rui-jie, WANG Ze-zhou, CAI Yong: Reliability and validity of defeat scale on anxiety and depression in medical students. Journal of Shanghai Jiaotong University(Medical Science) 2019, 39(1):84-88.

34. Zimet GD, Powell SS, Farley GK, Werkman S, Berkoff KA: Psychometric characteristics of the Multidimensional Scale of Perceived Social Support. J Pers Assess 1990, 55(3-4):610-617.

35. Sijian YJL: Investigation of depression status of type 2 diabetic patients live in community and relative factors. CHINESE JOURNAL OF NURSING 2009, 44(7):658-660.

36. Van Orden KA, Joiner TE, Jr., Hollar D, Rudd MD, Mandrusiak M, Silverman MM: A test of the effectiveness of a list of suicide warning signs for the public. Suicide Life Threat Behav 2006, 36(3):272-287.

37. Li Xiaomin XT, Yuan Jing, Lv Lixia, Tao Jiayu, Liu Yong: Validity and Reliability of the Interpersonal Needs Questionnaire in Chinese College Students. Chinese Journal of Clinical Psychology 2015, 23(4):590-593.

38. Dyrbye LN, Thomas MR, Massie FS, Power DV, Eacker A, Harper W, Durning S, Moutier C, Szydlo DW, Novotny PJ et al: Burnout and suicidal ideation among U.S. medical students. Ann Intern Med 2008, 149(5):334-341.

39. Rotenstein LS, Ramos MA, Torre M, Segal JB, Peluso MJ, Guille C, Sen S, Mata DA: Prevalence of Depression, Depressive Symptoms, and Suicidal Ideation Among Medical Students: A Systematic Review and Meta-Analysis. JAMA 2016, 316(21):2214-2236.

40. Li S, Yaseen ZS, Kim H-J, Briggs J, Duffy M, Frechette-Hagan A, Cohen LJ, Galynker II: Entrapment as a mediator of suicide crises. BMC Psychiatry 2018, 18(1):4-4.

41. Russell K, Rasmussen S, Hunter SC: Insomnia and Nightmares as Markers of Risk for Suicidal Ideation in Young People: Investigating the Role of Defeat and Entrapment. J Clin Sleep Med 2018, 14(5):775-784.

42. Teismann T, Forkmann T: Rumination, Entrapment and Suicide Ideation: A Mediational Model. Clin Psychol Psychother 2017, 24(1):226-234.

43. Hallensleben N, Glaesmer H, Forkmann T, Rath D, Strauss M, Kersting A, Spangenberg L: Predicting suicidal ideation by interpersonal variables, hopelessness and depression in real-time. An ecological momentary assessment study in psychiatric inpatients with depression. European Psychiatry 2019, 56(1):43-50.

44. Stenzel JS, Holler I, Rath D, Hallensleben N, Spangenberg L, Glaesmer H, Forkmann T: Do Feelings of Defeat and Entrapment Change over Time? An Investigation of the Integrated Motivational-Volitional Model of Suicidal Behaviour Using Ecological Momentary Assessments. Int J Environ Res Public Health 2020, 17(13).

\section{Figures}




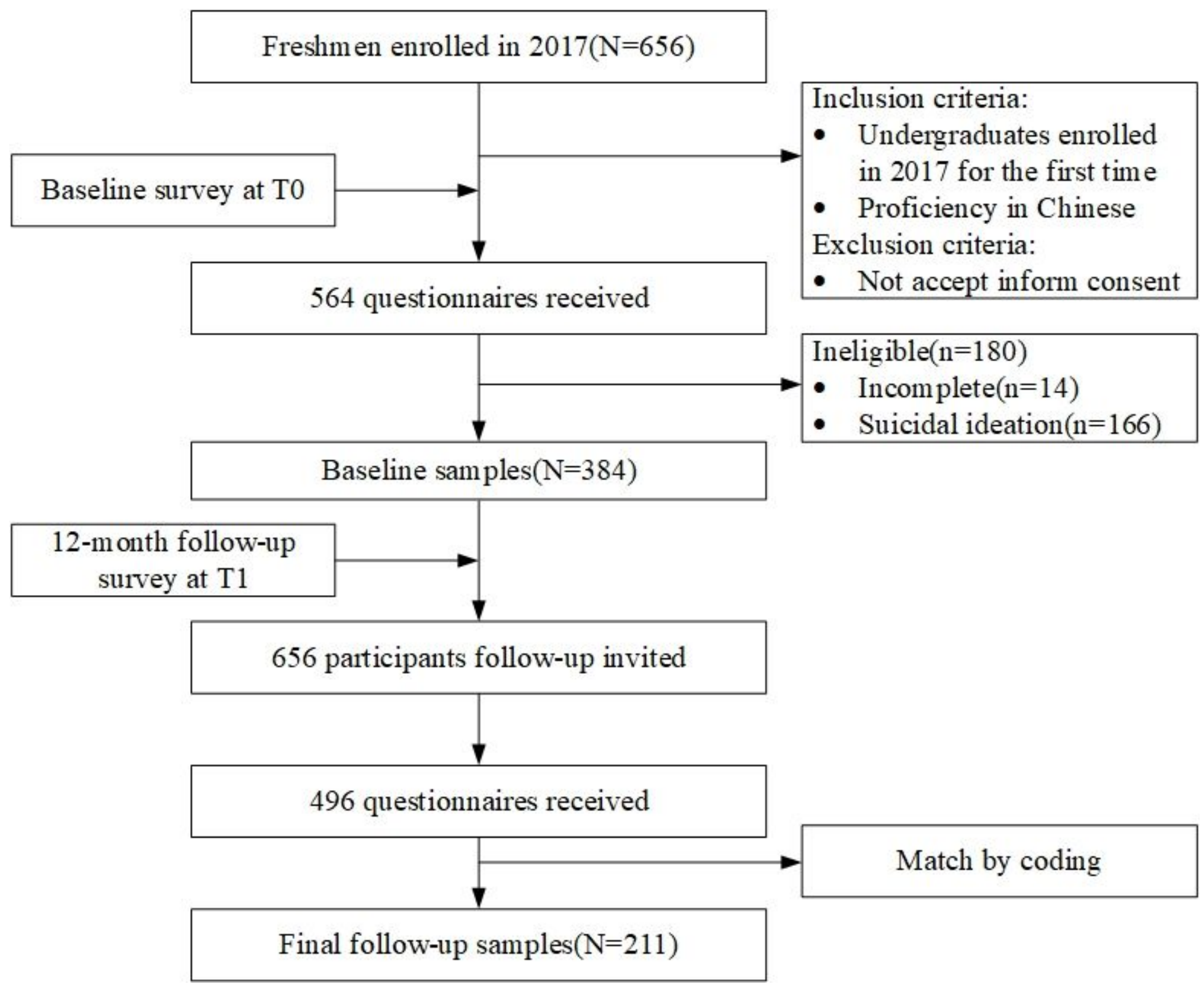

Figure 1

Flow-chart of study population.

\section{Supplementary Files}

This is a list of supplementary files associated with this preprint. Click to download.

- Supplementmaterials.docx 